УДК 130.1\3.(470.67)

DOI: $10.21779 / 2500-1930-2018-33-3-53-58$

К.М. Алилова ${ }^{1,2}$

Социоприродность мышления и экогуманизм в культуре и традициях Дагестана

1 Дагестанский государственный университет; Россия, 367001, Махачкала, ул. М. Гаджиева, 43a; kalimat2@mail.ru;

2 Дагестанский государственный университет народного хозяйства; Россия, 367008, г. Махачкала, ул. Д. Атаева, 5

Мы готовы срубить дерево, если нам нужна зубочистка.

Роберт Лембке - немеикий журналист.

Человек совершил огромную ошибку, когда возомнил, что может отделить себя от природы и не считаться с ее законами.

В.И. Вернадский - русский и советский учёньй-естествоиспытатель, мыслитель и общественный деятель.

В статье говорится об экологической ситуации, складывающейся сегодня на Земле. Раскрываются понятия социоприродности мышления (необходимость жить в гармонии с природой) и экогуманизма (шанс, данный человечеству не просто хорошо жить, а принимать участие в коллективном созидании цивилизации). Для этого необходимы умеренное потребление природных ресурсов и усилия, направленные на их воспроизводство, и воссоздание духовных ценностей. В современной сложной социально-культурной, социально-экологической ситуации, перед лицом экологического кризиса поиск путей устойчивого развития как оптимальной регуляции отношений человека и бытия остального мира имеет особую значимость. Человечество сегодня ориентировано на деньги и успех. Эта ориентация и вызывает экологический кризис.

В статье рассматриваются особенности дагестанской экологической культуры, уважительное отношение к природе у дагестанских народов складывавшееся на протяжении веков, что позволяет надеяться на дальнейшее конструктивное преодоление социально-экологических противоречий глобального и регионально-национального уровня, так как в Дагестане экология исторически была частью национальной культуры. Народные представления о природе определяются в результате познания ее законов, основанных на наблюдениях и опыте практической деятельности. Передавая из поколения в поколение трудовые навыки, духовные ценности как приоритет экологической и общей культуры, горцы на протяжении веков рационально использовали природные богатства родной земли.

Ключевые слова: социоприродное мышление, экогуманизм, экология, экологическая кульmypa.

Еще в середине прошлого столетия американский философ и математик Норберт Винер возмущался экологическим невежеством большинства жителей планеты. «Мы столь радикально изменяли природную среду, что теперь для того, чтобы благополучно существовать в ней, мы должны изменить себя», - писал он. Прошли десятилетия, а экологическая угроза окружающей среде не стала меньше.

Тенденция сегодняшнего мира - войны из-за природных ресурсов, где, к сожалению, гибнут люди. Во многих странах уже не хватает питьевой воды. Нынешнюю ситуацию можно определить как стремление некоторых стран силой показать свое превос- 
ходство и право единолично использовать ресурсы остального мира. Например, многие страны возмушены тем, что у России слишком большое количество природных ресурсов, и считают, что даже озеро Байкал не должно принадлежать только ей. Исходя из этого, проблема соотношения природы и человека сегодня затрагивает всех независимо от национальности и религиозной принадлежности [1, с. 256].

Вопросы экологического характера возникали у человечества на протяжении всей его истории. Забота о природе, выражаемая чаще всего в форме запретов, была характерна первобытным людям. Например, у северных народов такое отношение сохранилось до сих пор. Если ненец на охоте «встретится с медведем, то он тотчас его не убивает, а сначала вступает с ним в разговор, начинает восхвалять его достоинства, спрашивает, для чего он встретился с ним, просит, чтобы он не поцарапал его своими острыми когтями». После «беседы», во время которой медведь якобы соглашается быть убитым, охотник его убивает и «считает себя в своих действиях оправданным против родных медведя, которые за смерть своего члена могли бы отомстить» [2, с. 26].

В античную эпоху люди уже обладали знанием и понимали те проблемы, которые мы сегодня называем экологическими. Например, философская школа киников провозглашала идеалы ограничения потребностей.

В средневековой Европе, наоборот, происходила интенсивная вырубка лесов для нужд сельского хозяйства, судостроения, для строительства домов. Местные жители говорили, что становилось все больше «земель с ободранной шкурой».

В эпоху Возрождения природа не остается без внимания. Человек начинает понимать красоту и величие природы, и соответственно отношение к ней меняется.

Дальнейшее развитие прогресса и усиленное воздействие на природу заставляют человечество задуматься о последствиях. Эти проблемы требуют немедленного решения. Ситуация очень быстро осложняется и может стать необратимой. Поэтому всему мировому сообществу необходимо решать эти вопросы.

Развитие науки означает власть над природой, которой можно манипулировать по своему усмотрению. Чем больше мы контролируем природный мир, тем меньше мы его уважаем. К этому всему нужно добавить распространенные, но необоснованные представления, согласно которым жизнь растений и животных якобы скучна и безысходна, и что современная наука доказала, что природа механистична, лишена цели и свободы [3, с. 148].

Постепенно человечество осознало необходимость преодоления противоречий, связанных с деятельностью человека, и установления гармонии с природой. Такое мировоззрение обусловлено эволюционной сущностью социоприродности мышления.

Необходимо сказать, что в философии социоприродности мышления наиболее отчетливо обозначились два логико-диалектических аспекта взаимоотношений человека и природы: с одной стороны, человек является частью быстро изменяющейся среды обитания, которая зависит от природной целостности. С другой - сам человек представлен как фактор природной и социальной эволюции: он развивал свои способности таким образом, что, создавая новую технику, начинал активно влиять на природу. В современной сложной социально-культурной, социально-экологической ситуации, перед лицом экологического кризиса поиск путей устойчивого развития как оптимальной регуляции отношений человека и бытия остального мира имеет особую значимость [4, c. 100].

Подобное мышление присуще экогуманизму, воспринимающему человека как неотъемлемую, органическую часть природы и вместе с тем как ключевое творческое звено природы, закономерно претендующее на лидерскую, организующую роль. Но- 
осфера - область человеческого разума, культуры и социальных отношений - является логическим продолжением эволюции живой материи. Экология антропогенного мира должна рассматриваться в неразрывной связи с экологией натуральных сообществ [5]. Главное в философии экогуманизма - это жизнь человека, его шанс не просто хорошо жить, а принимать участие в коллективном созидании цивилизации. Экогуманизм выступает за охрану жизни человека до его естественного ухода. Поэтому необходимы: совершенствование отношений с природой, умеренное потребление, забота о ближнем, усилия, направленные на воспроизводство природных ресурсов и духовных ценностей. К этим духовным ценностям относятся культура и традиции, в том числе экологические.

Сегодня много говорят о деградации человека. Этим мы платим по счетам за достигнутый прогресс. Можно возразить: мало ли что говорят? Однако внутренняя упрощённость современного человека, порой явная его опустошённость - это, увы, факт. Люди сегодня ориентированы чаще всего на деньги, на успех. То, что было пороком, стало нормой $[6$, с. 35]. Все это и вызывает так называемый экологический кризис.

В дагестанской экологической культуре уважительное отношение к природе как к части общей культуры дагестанских народов складывалось на протяжении веков.

Дагестан - одна из самых живописных республик Российской Федерации. Это земля заповедников, уголок удивительной природы. М.Ж. Курбанов в своей статье «Забота о природе» пишет, что процветание Дагестана напрямую связано с сохранением его территориальной целостности, природного и культурного богатства, обеспечением благоприятной среды обитания и экологической безопасности, высоким интеллектуальным и нравственным потенциалом граждан. В Дагестане во все времена охраняли лесные массивы, отдельные виды деревьев, животных, водные ресурсы. Об этом свидетельствуют исторические факты, фольклор, легенды народов нашей республики [7, с. 3].

В дошедших до нас литературных источниках говорилось о том, что народы Дагестана всегда заботились о природе. Многие животные и птицы, колодцы, даже отдельные деревья в горах считались священными. В ауле Заза Хивского района к дереву Чанлар-так люди приносили дары, просили о помощи. В преданиях с. Кунки, Худуц Дахадаевского р-на, с. Варсит Кайтагского р-на, с. Ретлоб, Гунзиб Цунтинского р-на сказано: «С того, кто срубит дерево в охраняемом лесу, загрязнит стиркой воду в колодце, будет пасти скот на запрещенных землях, лесах, взыскивается штраф в размере 1-3 овец, 2-4 мерок зерна». У урахинского джамаата был большой лес Начзала-илала. Тот, кто срубал в лесу дерево, подвергался штрафу в размере одного быка. Пастух не имел права пасти скот на запрещенных землях общества. Водным объектам (родники, источники, ключи) в районах Дагестана с давних времен давали названия, носившие религиозный, патриотический, антропонимический характер. Это, например, «Дармансу» в с. Гильяр Магарамкентского района, «Нур-булах» (святой источник) в с. Захит Хивского района.

Родники передавались по наследству, их называли в честь выдающихся людей местности, за ними ухаживали потомки. Во всех районах Дагестана издревле отмечали и до сих пор отмечают: Праздник первой борозды, День чабана, Праздник цветов, Праздник черешни, Праздник урожая, Неделя сада, Праздник воды, Праздник виноградаря, Праздник садовода. Их особенностью является то, что они побуждают любовь к природе, способствуют охране и воспроизводству природных ресурсов. В период проведения праздников устанавливаются общественные правила, связвнные с охраной природы [8, с. 2]. 
Во многих аулах Дагестана сохранились народные традиции по охране природы. Так, при рождении сына родители сажали деревья и ухаживали за ними. При рождении внука дед сажал деревья вокруг родника, благоустраивал его, следил за ним.

Горцы на протяжении веков рационально относились к природе и богатствам родной земли.

Профессор 3.А. Шахмарданов, описывал экологические проблемы народов Дагестана, отмечает, что в XVIII веке появился окончательно усовершенствованный сельскохозяйственный календарь. Он устанавливал сроки: проведения всех видов работ земледельческих, животноводческих; изготовления сельскохозяйственных орудий, обустройства каналов для полива садов, очищения пастбищ от кустов и мусора.

Различные исторические периоды в Дагестане характеризовались определенными формами народной экологической дипломатии.

Предания, дошедшие до наших дней, свидетельствуют о том, что все народы Дагестана охраняли лесные массивы, отдельные деревья, животных и птиц, считая их священными.

Встречаются памятники дагестанского экологического права, которые содержат правила и положения, регулирующие отношения между человеком и природой. В поговорках также наблюдается трепетное отношение к окружающей природе: «Дозволено убивать даже мудреца-алима, если он срубит дерево» [9, с. 12].

Лес всегда кормил, одевал, поил, обогревал и лечил человека. Дерево, кроме плодов и ягод, давало сок; мякоть отдельных пород шла в пищу; дерево служило сырьем для изготовления ёмкостей, посуды, оружия, благовоний, смол, лучины, стройматериалов и т. д.

Необходимо возрождать традиции предков по охране природы, учитывая современные этнополитические, культурные, социально-экономические особенности. Если не изменить хищническое отношение к природе, то могут начаться необратимые негативные процессы, мы можем потерять богатство, красоту и уникальность природы нашего горного края.

Заповедники и природные парки являются гордостью Дагестана. Они нуждаются в защите и заботе. Первостепенная задача нынешней власти - сохранить неповторимость флоры и фауны.

Например, 22 мая 2018 г. на базе Дворца детского творчества в Буйнакске состоялась Всероссийская акция «Сделаем вместе!». В акции приняли участие депутат Народного Собрания РД Зумруд Бучаева, заместитель министра природных ресурсов и экологии РД Арслан Сайпулаев, главный специалист-эксперт Министерства природных ресурсов и экологии РД Наби Мусалаев, руководство города. Выступающие отмечали, что экологическое воспитание детей, подростков и молодежи, формирование ответственности за окружающий мир, вовлечение подрастающего поколения в защиту окружающей среды позволит сохранить её и обеспечить порядок в данной сфере [10].

Эти и многие другие факты из истории и современности свидетельствуют о том, что социоприродность мышления и экогуманизм, характерные для дагестанской культуры, будут способствовать дальнейшему развитию этических оценок в сфере нарушений природопользования и бездумного отношения к окружающей среде. Необходимо также конструктивное преодоление социально-экологических противоречий глобального и регионально-национального уровня.

История народов Земли показывает: тот, кто забыл ее уроки, кто не понимает, что его деятельность оказывает губительное воздействие на природу, тот отнимает жизнь у своих потомков. Как предупреждение потомкам звучит иероглифическая надпись на 
пирамиде Хеопса: «Люди погибнут от неумения пользоваться силами природы и от незнания истинного мира».

\title{
Литература
}

1. Алилова К.М. Образование для устойчивого развития: философский аспект // Юг России: экология и развитие. - 2016. - Т. 11, № 3. - С. 256.

2. Вдовин И.С. Природа и человек в религиозных представлениях народов Сибири и Севера. - М., 1976. - С. 26.

3. Абдурахманов Г.М., Кулиев T.T. Теоцентризм и антропоцентризм в современном экологическом сознании // Юг России: экология, развитие. - 2012. - № 2. - С. 148.

4. Сыдыкбеков Р.Д. Социоприродное мышление киргизов в контексте традиционной этнической культуры // Педагогическое образование в России. - 2016. - № 1. C. 100 .

5. Манифест экогуманизма - URL: https://vrns.ru/united-society/4647 (дата обращения 26. 05.2018).

6. Скитниевский B. Зов бытия. Об экзистенциальном измерении читателя // Библиотечное дело. - 2011. - № 17. - С. 35.

7. Курбанов М.Ж. Забота о природе в наших традициях // Народы Дагестана. 2009. - № 6. - С. 3 .

8. Шахмарданов 3.А. Современные проблемы народов Дагестана // Народы Дагестана. - 2016. - № 4. - С. 2.

9. Агларов М.A. Сельская община в Нагорном Дагестане в VII-XIX вв. - M., 1988. - C. 12.

10. http://www.mprdag.ru/press-tsentr/novosti/vserossiyskaya-ekologicheskaya-aktsiyasdelaem-vmeste-proshla-v-buynakske-338 (дата обращения 02.06.2018).

Поступила в редакциюю 26 июня 2018 г.

UDC 130.1\3.(470.67)

DOI: $10.21779 / 2500-1930-2018-33-3-53-58$

\section{Social nature of thinking and ecohumanism in the culture and traditions of Dagestan}

\author{
K.M. Alilova ${ }^{1,2}$ \\ 1 Dagestan State University; Russia, 367001, Makhachkala, M. Gadzhiev st., 43a; \\ kalimat2@mail.ru; \\ ${ }^{2}$ Dagestan University of national economy; Russia, 367008, Makhachkala, D. Ataev st., 5
}

The article deals with the ecological situation that is developing today on the Earth. The concepts of the social nature of thinking are revealed as a necessity to live in harmony with nature and ecohumanism, as the chance of mankind is not just to live well, but to participate in the collective creation of civilization. This requires moderate consumption and efforts aimed at the reproduction of natural resources and spiritual values. In the current complex socio-cultural, social and environmental situation, in the face of environmental crisis, the search for sustainable development as an optimal regulation of human relations and the life of the rest of the world is of particular importance. Mankind 
today is focused on money and success. This orientation causes what is now called the ecological crisis. The article shows the peculiarities of Dagestan's ecological culture, where people's respect for the nature has developed over the centuries. This allows us to hope for further constructive overcoming of social and environmental contradictions of both global and regional-national level since ecology was historically based on the national culture in Dagestan. People's knowledge of nature is determined by knowledge of the laws of nature, based on observations and experience of practical activity. Through the transition from generation to generation of work skills, spirituality as a priority of ecological and general culture, the mountaineers throughout the centuries provided rational nature management, consciously and reasonably referring to the use of the natural resources of their native land.

Keywords: socio-natural thinking, ecohumanism, ecology, ecological culture.

Received 26 June, 2018 